Quando eu cursava o Programa de Mestrado em Ortodontia da FOBauru-USP, tive a oportunidade de conhecer o Prof. Ary dos Santos Pinto. Foi quando ele estava participando como convidado de uma banca de defesa de Mestrado. Impressionou-me a sua forma de dirigir-se ao candidato, por sua extremada educação ao perguntar, humildade em partilhar seus conhecimentos, bem como respeito ao momento tão particular que é uma defesa de pós-graduação. Cerca de 6 anos depois, tive a felicidade de cursar o programa de Doutorado na FOAraraquara-UNESP, coordenado pelo professor Ary. Além do aprendizado técnico-científico, pude aprender e amadurecer com os professores daquele programa, pela forma amistosa de compartilhar o conhecimento e suas experiências. Especialmente o Professor Ary continuava a destacar-se pela gentileza no seu modo de lidar com todos. A sala dele sempre estava cheia de alunos ávidos por conhecimento, mas além disto, tranqüilos por saberem que mesmo se passasse do horário de trabalho, ele permaneceria lá com a mesma paciência para atender a todos. Sua carreira acadêmica há pouco tempo ganhou mais um importante degrau, a Livre-Docência, em cujo concurso desempenhou com brilhantismo os requisitos exigidos. Sua excelente formação científica foi reforçada pelo amadurecimento adquirido no periodo em que passou por Dallas e Seattle nos EUA.

Esta entrevista em que participaram os ex-alunos Adriano Marotta Araujo, Ricardo Sampaio de Souza, Daltro Enéas Ritter, Paulo César Ravelli Chiavini, Roberto Hideo Shimizu, bem como o amigo e professor Dirceu Barnabé Raveli, aborda um pouco do que pôde pesquisar em suas andanças acadêmicas, bem como de sua ampla experiência clínica.

Obrigado professor Ary dos Santos Pinto por aceitar prontamente o convite da Revista Dental Press de Ortodontia e Ortopedia Facial e dividir um pouco de seu vasto conhecimento?

- Prof. Adjunto do Departamento de Clinica Infantil - Ortodontia da Faculdade de Odontologia de Araraquara - UNESP.

- Formado em Odontologia pela Faculdade de Odontologia de Araçatuba - UNESP em 1980

- Realizou curso de Pós-Graduação em Ortodontia, Mestrado (1982-84) e Doutorado (1984-91) na Universidade Federal do Rio de Janeiro (UFRJ).

- Realizou Pós-Doutorado na Baylor College of Dentistry em Dallas - TX (1996-97).

- Professor da Disciplina de Ortodontia do Departamento de Clínica Infantil da Faculdade de Odontologia de Araraquara - UNESP desde 1984.

- Professor Livre-Docência no Departamento de Clínica Infantil - Disciplina de Ortodontia da Faculdade de Odontologia de Araçatuba - UNESP a partir de 2001

- Professor dos cursos de Mestrado e Doutorado em Ortodontia do Programa de Pós-Graduação em Ciências Odontológicas da Faculdade de Odontologia de Araraquara - UNESP dos cursos de Especialização em Ortodontia e Ortopedia Facial da Fundação de Amparo ao Ensino e Pesquisa em Odontologia (FAEPOUNESP), do Grupo de Estudos Ortodônticos e Serviços de Araraquara (GESTOS -FAMOSP) e do Centro de Aperfeiçoamento Profissional de Sertãozinho (CAPES-CIODONTO).

- Consultor científico da Revista Dental Press de Ortodontia e Ortopedia Facial, da Revista da Sociedade Brasileira de Ortodontia e da Revista Gaúcha de Ortodontia e Ortopedia Facial.

\section{Ary dos Santos Pinto}

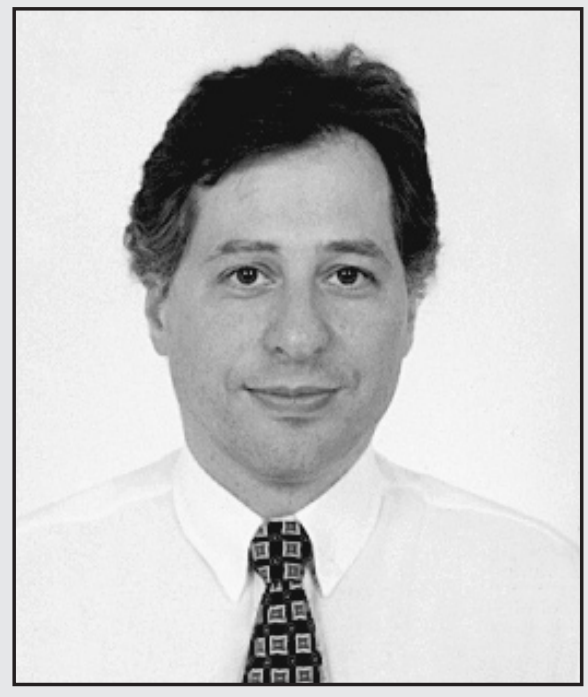

1) Sabemos que o crescimento craniofacial é um dos seus campos de pesquisa. Foi comprovado que o padrão de rotação mandibular é um componente decisivo na determinação da má oclusão de Classe II de Angle. Seria possível mudar, com o tratamento ortopédico, 0 padrão de rotação mandibular do paciente? Hoje qual seria seu protocolo de tratamento e aparatologia na correção da má oclusão de Classe II esquelética em pacientes jovens com padrão vertical de crescimento? Adriano Marotta Araujo
As teorias vigentes sobre crescimento e desenvolvimento apontam para um controle genético das estruturas craniofaciais, modificadas por fatores epigenéticos gerais, locais e ambientais. Os trabalhos realizados no programa de pós-graduação em Odontologia, área de Ortodontia da UNESP de Araraquara, com pacientes Classe II tratados com aparelho ortopédico, alguns dos quais você conduziu, além dos dados da literatura, mostram de forma inequívoca que o crescimento mandibular pode ser alterado. Os aparelhos ortopédicos funcionais propulsores da mandíbula desviam o crescimento do 
côndilo numa direção mais posterior, inibem a rotação do corpo mandibular em relação ao ramo (rotação intra-matriz), normalmente no sentido antihorário, em indivíduos braquifaciais ou mesofaciais e modificam o padrão de remodelação mandibular, em direção a um padrão que é mais característico de indivíduos dolicofaciais. Assim, pacientes baquifaciais tem seu padrão de crescimento, eminentemente horizontal, desviado numa direção mais vertical e favorável com o uso destes aparelhos que tornam seu crescimento facial mais harmonioso, equilibrando a altura facial diminuída. Associada a esta ação mandibular, o aparelho promove uma leve restrição do crescimento anterior da maxila, um aumento da rotação maxilar no sentido anti-horário, com descida da espinha nasal posterior, auxiliando no aumento da altura facial reduzida nas crianças braquifaciais. Nos trabalhos sobre crescimento mandibular que tive oportunidade de realizar com o prof. Peter Bushang em Dallas - Texas e dados de outros trabalhos indicam que a rotação intra-matriz mandibular no sentido anti-horário é um dos mecanismos mais importantes no posicionamento do mento para anterior. Assim, os aparelhos ortopédicos funcionais que utilizam a propulsão terapêutica da mandíbula tem sua ação no sentido oposto ao desejado em termos de rotação intra-matriz e desta forma não atuam de forma tão efetiva quando o efeito que se deseja é um posicionamento mais anterior da mandíbula. Indiretamente, conseguimos uma rotação matriz (diminuição da inclinação do plano mandibular) e menor interferência na rotação intra-matriz com o uso de aparelhos extrabucais com cobertura oclusal e tração alta. Na Classe II esquelética associada a padrão vertical de crescimento, o uso de acrílico interposto entre os dentes posteriores (Bite block) resulta em ação restritiva do crescimento vertical dentoalveolar e maxilar, com rotação matriz mandibular no sentido anti-horário (diminuição da inclinação do plano mandibular). $\mathrm{O}$ aparelho de Klammt, quando construído com apoio de acrílico na região posterior, se assemelha ao Bite block, mas tem como diferencial a possibilidade de avanço postural mandibular e a utilização de arcos bucinadores e escudos linguais de acrílico, que re- movem a pressão da musculatura externa (bucinadores e orbiculares) e interna (língua). A vantagem deste aparelho sobre o anterior é a possibilidade de atuar sobre o crescimento transversal dos arcos dentários pela ativação da mola de Coffin. Considero que o aparelho extrabucal de Thurow modificado seja o aparelho de maior ação vertical dentro do arsenal ortodôntico e ortopédico que está à disposição do ortodontista. Este aparelho combina a ação do Bite block acrescida da força vertical extrabucal, que potencializa os efeitos de inibição do crescimento vertical dentoalveolar e do complexo nasomaxilar. A força extrabucal pode ser direcionada de forma a se obter uma rotação maxilar no sentido horário ou anti-horário, simplesmente pela manipulação do comprimento ou inclinação da asa externa do arco extrabucal em relação à asa interna. $\mathrm{Na}$ maioria das vezes, nos pacientes Classe II verticais que apresentam mordida aberta anterior, desejamos uma rotação horária da maxila, que pode ser obtida pela orientação da linha de ação de força do aparelho extrabucal posterior em relação aos centros de resistência da maxila e arco dentário (arco externo mais longo e horizontal). Quando desejamos manter a inclinação da maxila, a linha de ação de força do aparelho extrabucal é então direcionada ao centro de resistência da maxila e arco dentário cortando-se o arco externo na linha do canto de olho ou angulando um arco externo de tamanho médio por volta de 45 graus em relação ao arco interno. A dimensão vertical da face é a última a completar seu crescimento pleno, favorecendo um longo período de atuação. Em indivíduos com padrão vertical, o estabelecimento de uma respiração normal e orientação no sentido de fortalecimento dos músculos da mastigação por meio de exercícios podem influir de forma favorável no crescimento facial vertical (mais anterior e menos vertical) e estimular a mandíbula a exibir maior rotação intra-matriz anti-horária, com resultante posicionamento do mento mais anterior, conforme demonstrado por Bushang. Considero que a fase ideal para se realizar este tipo de intervenção seria no período inter-transitório da dentadura mista, isto é, após a completa erupção dos incisivos, por volta dos 10 anos de idade, quando 
o paciente está em aceleração do seu crescimento geral e facial e próximo ao seu pico de velocidade. Até a queda dos $2^{\text {os }}$ molares decíduos, teríamos por volta de 1 a 2 anos para atuarmos de forma efetiva com os aparelhos relacionados anteriormente. Após esta fase, teríamos uma nova oportunidade de atuação na fase de dentadura permanente jovem, por volta dos 12 anos de idade, já contando com o apoio dos pré-molares e com uma velocidade de crescimento máxima (surto de crescimento pubertário). Não devemos nos esquecer que as meninas nesta fase estão mais adiantadas que os meninos, em seu ritmo de crescimento, e mais próximas do final do surto de crescimento que os meninos, que irão finalizar seu surto por volta de 1 a 2 anos mais tarde.

2) Os aparelhos propulsores da mandíbula proporcionam a correção dentoalveolar da má oclusão de Classe II, quando utilizados em pacientes com crescimento. Qual a sua opinião sobre o postulado existente de que essa terapia é capaz de fazer a mandíbula crescer mais do que o normal no sentido ântero-posterior? Seria isso possível? Adriano Marotta Araujo

Considero que os aparelhos ortopédicos liberam o potencial de crescimento condilar que é endocondral em sua essência e pouco influenciado pelas forças de tensão ou compressão aplicadas a ele, mas que estruturalmente tem grande poder de adaptação à influência ambiental. Nos trabalhos que tive oportunidade de participar e orientar em Araraquara, e nos dados da literatura, constatamos pequeno incremento no crescimento condilar que parece ser "antecipado" pela ação dos aparelhos ortopédicos. Por outro lado, é muito evidente a ação destes aparelhos sobre a estrutura óssea mandibular, que tem a remodelação óssea como principal forma de crescimento pós-natal. Assim, nitidamente, temos uma mudança no padrão de remodelação óssea, marcadamente representada pelo redirecionando do crescimento do côndilo e ramo mandibular para posterior, que abre o ângulo goníaco e torna o comprimento efetivo mandibular maior (distância do côndilo à sínfise mentoniana). Pode-se dizer que o aparelho ortopédico modifica a matriz funcional mandibular devido à propulsão terapêutica efetuada nos casos de Classe II com retrusão mandibular pelo estiramento dos tecidos moles, modificação da atividade eletromiográfica dos vários músculos que fazem sua inserção no corpo, ramo e processos coronóide e condilar, modificação da postura lingual e do equilíbrio muscular interno (língua) e externo (orbiculares e bucinadores), modificação da postura dos lábios e em alguns casos pelo aumento do espaço bucofaringeano. Existe uma falsa idéia de que os aparelhos ortopédicos tenham como função primária promover um aumento do crescimento mandibular. Uma alteração do padrão de rotação do complexo naso-maxilar e mandibular, muitas vezes, é o efeito desejado num tratamento ortopédico. A região dentoalveolar, conforme você coloca no seu questionamento, é profundamente afetada pela ortopedia e em grande intensidade, pois é uma área altamente adaptativa e suscetível a mudanças frente à ação ambiental (funcional). Um dos grandes desafios a serem vencidos pelos aparelhos ortopédicos no tratamento dos problemas esqueléticos está na sua maior ação dentoalveolar, por volta de $70 \% \mathrm{em}$ relação à ação esquelética. $\mathrm{O}$ uso destes aparelhos na fase de surto de crescimento pubertário e o avanço escalonado da mandíbula são recomendados como forma de obtenção de maior ação "ortopédica".

3) Quando consideramos o tratamento da mordida profunda em pacientes adultos, várias são as mecânicas existentes. Destacamos a técnica do arco segmentado de Charles Burstone, que oferece diversos dispositivos e grande controle dos procedimentos. Porém, a estabilidade dos resultados obtidos ainda é um desafio para os especialistas da área. Como poderíamos minimizar uma possível recidiva? Qual seu protocolo de contenção nesses casos? Adriano Marotta Araujo

A técnica do arco segmentado fornece uma metodologia segura biologicamente, simples, prática e eficiente para o tratamento da mordida profunda. A intrusão pode ser conseguida por translação ou com inclinação vestibular ou lingual dos dentes anteriores, para isto basta direcionar a linha de ação de força 
respectivamente no centro de resistência, anterior ou posterior ao centro de resistência dos dentes anteriores. O sucesso e estabilidade da intrusão, tanto em pacientes jovens quanto em adultos, está na obtenção de uma correta inclinação interincisal, por volta de 132 graus. Incisivos que foram muito intruídos e que foram finalizados muito verticais são mais suscetíveis à recidiva. A correção da sobremordida, quando conseguida pela extrusão de molares, é mais estável, porém em pacientes adultos pode ser prejudicial à estética facial e resultar em aumento da convexidade facial e retrusão mandibular. Em pacientes jovens, o crescimento facial pode compensar a extrusão de molares e neste caso uma boa estabilidade seria conseguida. A contenção recomendada para os casos de intrusão absoluta de incisivos, principalmente em pacientes adultos, é a utilização de placa de contenção com plano de mordida ou batente anterior, que evitaria movimento vertical dos dentes inferiores. $\mathrm{O}$ arco vestibular da placa de contenção aliado à inclinação dos incisivos superiores evitaria movimentos verticais ou recidivas destes dentes. A sobrecorreção ainda é a melhor forma de minimizar a recidiva quando realizamos intrusão de incisivos.

4) Atualmente, o senhor se destaca por ser um dos grandes investigadores no campo da Ortodontia e Ortopedia Facial e por ser um grande conhecedor de metodologia e desenvolvimento de trabalhos científicos. Também sabemos da existência de muitos cursos de pós-graduação em atividade. Como considera a situação da pesquisa hoje na área de Ortodontia no Brasil? Adriano Marotta Araujo

A pesquisa científica na área da Ortodontia brasileira tomou um impulso nas últimas décadas. A formação científica passou a ter prioridade em relação à formação técnica, tradicionalmente enfatizadas nos cursos de pós-graduação, incentivada pela forma de avaliação adotada pela CAPES. O incremento na massa de pesquisadores qualificados no Brasil resultou da formação oferecida nos programas de pós-graduação tradicionais aliada à abertura de novos programas, núcleos e pólos em diversas partes do Brasil. Outros aspectos foram de- cisivos, tais como a participação dos pesquisadores em programas de pós-doutorado no exterior, financiamento das pesquisas pelas agências de fomento (CAPES, CNPq, Fapesp no nosso estado e outras agências de fomento estaduais), acesso facilitado à literatura nacional e internacional devido ao desenvolvimento da internet e à ampliação e melhora dos meios de divulgação nacionais, tendo como exemplo a Revista Dental Press de Ortodontia e Ortopedia Facial que, com sua qualidade editorial e científica, é hoje referência internacional e tem nível de excelência Qualis A. Houve uma revolução na visão tradicional, no preparo e condução dos trabalhos científicos, demonstrada pela forte presença nacional em publicações no exterior.

5) $\mathrm{Na}$ Ortodontia sempre aparecem aparelhos que dizem substituir 0 arco extrabucal. Existe algum que se assemelha a ele na correção da má oclusão de Classe II de Angle em pacientes em crescimento? Ricardo Sampaio de Souza

$\mathrm{Na}$ minha opinião, não existe nenhum aparetho similar à força extrabucal aplicada aos arcos dentários com a finalidade de movimentação dentária ou ortopédica. A versatilidade em termos de aplicação de forças e a possibilidade de direcionamento variável desta força, conforme a ação desejada, fazem do aparelho extrabucal um aparelho de amplo espectro insubstituível, principalmente se a finalidade é uma ação específica sobre o complexo nasomaxilar. Devemos utilizar bases sólidas de conhecimento e discernimento, pautadas em bom diagnóstico na indicação deste aparelho. Não devemos nos deixar seduzir pela propaganda milagrosa e excepcional de aparelhos que supostamente substituem o aparelho extrabucal, evitando soluções personalistas, cujos resultados não resistem a uma avaliação mais criteriosa e de longo prazo. Assim, aparelhos distalizadores intrabucais tais como Pendex, Pêndulo, Jones jig e similares, que foram desenvolvidos com o intuito de substituir o aparelho extrabucal, hoje tem sua indicação restrita. Os aparelhos intermaxilares, tais como os vários modelos de Herbst, Jasper jumper, Forçus 
e Aparelho de Protração Mandibular (APM) e outros similares, têm formas de atuação e indicações específicas, diferentes da forma de atuação e indicação dos aparelhos extrabucais. $\mathrm{O}$ aparelho extrabucal, em décadas passadas, foi utilizado de forma intensa e indiscriminada, conferindo em certos casos um aspecto facial chamado face ortodôntica, caracterizado pela rotação maxilar e mandibular no sentido horário, enquanto o nariz, com seu crescimento anterior preponderante, marcava a face com aspecto hiperdivergente, mas hoje tem suas indicações bem delimitadas.

6) Existem divergências entre ortodontistas com relação à vestibularização dos incisivos inferiores. Qual o limite para vestibularizar estes dentes sem dano aos tecidos de suporte e para a estabilidade do tratamento ortodôntico? Ricardo Sampaio de Souza

A posição dos incisivos inferiores é um dos dogmas da Ortodontia. Nossos sábios mestres já nos ensinavam que os incisivos inferiores poderiam ser mantidos em suas posições de equilíbrio morfofuncional quando estavam verticalizados em suas bases ósseas ou numa variação de até 5 graus e nos orientavam que deveríamos considerar o padrão de crescimento facial. Indivíduos com padrão de crescimento vertical (dolicofaciais) deveriam ter seus incisivos mais verticalizados ou levemente inclinados para lingual, enquanto aqueles com padrão horizontal (braquifaciais) poderiam ter seus incisivos levemente vestibularizados. Do ponto de vista biológico estas informações são coerentes, uma vez demonstrado por Bjork, Bushang e outros pesquisadores que pacientes dolicofaciais apresentam padrão de erupção dentária mais lingual, encurtando o perímetro de arco e pacientes braquifaciais apresentam padrão de erupção dentária mais vestibular, mantendo o perímetro do arco pela migração anterior dos dentes posteriores. Inclusive, esta erupção dentária no período pós-tratamento ortodôntico e no período pós-pubertário tem sido relacionada com o apinhamento tardio. Trabalhos relativos a danos aos tecidos de suporte, dentre os quais teses realizadas no nosso curso de pós-graduação, mos- tram que vestibularizações de incisivos de pequena monta não trazem prejuízos à crista óssea alveolar ou ao nível de inserção gengival. Dentre os tratamentos, naqueles realizados com aparelhos ortopédicos ou ortodônticos em períodos de crescimento pouca ou nenhuma interferência é notada, mas em pacientes adultos a possibilidade de iatrogenias é maior. $\mathrm{O}$ uso de forças intermitentes ou de grande intensidade, movimentos dentários de vai-e-vem e traumas oclusais teriam potencial de dano maior às estruturas de suporte.

7) A reabsorção radicular durante o tratamento ortodôntico é um fator que tira o sono de muitos colegas nossos. Quais condutas os mesmos devem ter para minimizar este problema em seus consultórios? Ricardo Sampaio de Souza

Tenho orientado trabalhos de tese prospectivos sobre reabsorção radicular e o que pude constatar, até o momento, é que a reabsorção tem causa multifatorial e inespecífica, sendo que a movimentação dentária pode ser um fator coadjuvante ou excitante. A fase de retração dos dentes anteriores constitui-se numa fase crítica do tratamento ortodôntico neste sentido. Movimentos de vai-evem, como afirmei anteriormente, tem potencial de dano às estruturas de suporte e a aplicação de forças sem intervalo de tempo suficiente para a regeneração de pequenas áreas lesadas é um convite à reabsorção radicular e da crista óssea alveolar também. A forma da raiz pode ser um indicativo de maior potencial de reabsorção, assim um bom exame clínico e anamnese são recomendados. A conduta básica para evitar reabsorção radicular na clínica ortodôntica é a utilização de forças leves, considerando o volume radicular e tipo de movimentação desejada, além de ativação da movimentação dentária em intervalos iguais ou superiores a 28 dias. Cuidados redobrados são recomendados em situações onde ocorreu trauma de incisivos, recente ou passado. Após o trauma, recomenda-se no mínimo três meses de repouso na movimentação ou remoção de forças que incidam sobre os dentes afetados antes do reinício da movimentação. 
Recomenda-se ainda um acompanhamento radiográfico periódico no sentido de monitorar e identificar reabsorções radiculares incipientes.

\section{8) Os miniimplantes para ancoragem estão} sendo cada vez mais utilizados no dia-a-dia da clínica ortodôntica. Os miniimplantes vieram facilitar o tratamento ortodôntico de quais más oclusões de difícil correção? Ricardo Sampaio de Souza

Os miniimplantes vieram auxiliar no controle de ancoragem durante o fechamento de espaços, na verticalicalização de molares e na intrusão dentária de uma forma geral. A euforia inicial com relação à sua utilização, sua aplicação de forma indiscriminada e aparente facilidade na sua colocação, hoje encontram bases mais sólidas de aplicação e principalmente de fundamentos biomecânicos que dimensionam sua real utilidade no tratamento das más oclusões. Os estudos têm progredido no sentido de fornecer protocolos de inserção, indicando as áreas ósseas mais favoráveis à sua utilização, o miniimplante ideal (tipo, comprimento e espessura), os parâmetros para sua carga (tempo, quantidade e forma de aplicação desta força) e por fim os aspectos biomecânicos (mecânica a ser empregada, direção e efeitos da força, injúrias ou desconforto causados aos tecidos moles, como exemplos). Assim, posso dizer que os miniimplantes vieram facilitar meu tratamento ortodôntico, mas também trouxeram vários pormenores que tem de ser corretamente realizados a fim de não serem motivo de frustração ou de problemas adicionais. Vejo os miniimplantes como realidade promissora.

9) A distração osteogênica tem surgido como opção para a correção de algumas más oclusões. Em quais casos este recurso auxilia no tratamento ortodôntico? Ricardo Sampaio de Souza

Temos realizado em nosso curso de pós-graduação a distração osteogênica médio sagital mandibular em casos onde existe uma atresia maxilomandibular, acompanhada por apinhamento localizado na região anterior inferior, principalmente. Neste campo, tenho acompanhado os trabalhos do prof. Luiz Gandini, que demonstram a utilidade do procedimento onde a distração é realizada na sínfise mandibular com auxílio de distrator dentosuportado, após disjunção da sutura palatina mediana. Os resultados são promissores, mas indicam a necessidade de acompanhamento em longo prazo no sentido de avaliação de seus reais efeitos dentoalveolares e esqueléticos e da estabilidade dos resultados obtidos. Em Dallas tive a oportunidade de acompanhar estudos sobre a distração osteogênica do corpo ou ramo mandibular e maxilar em casos de deformidades ou síndrome craniofaciais, mas não tenho utilizado destes procedimentos.

10) Em relação aos recentes avanços da Imaginologia, especificamente ao tomógrafo Cone Bean, quais as implicações e mudanças em relação aos atuais meios de diagnóstico? A radiografia cefalométrica poderá ser substituída por este meio de diagnóstico? Daltro Enéas Ritter

A tomografia Cone Bean veio para revolucionar o diagnóstico, planejamento e avaliação dos procedimentos na área da Odontologia em geral. A sua utilização em estudos de crescimento e avaliação da terapêutica ortodôntica e ortopédica ainda está começando. O custo de uma tomada e a baixa dose de radiação, aliadas à possibilidade de obtenção de imagens tridimensionais gerais, localizadas ou específicas de tecidos moles, tecidos duros ou ósseos, são realmente animadoras e fantásticas. As limitações que existiam no exame radiográfico tradicional foram suplantadas e estudos antes impossíveis de serem realizados já estão se tornando realidade. O limite do que pode ser realizado será o do conhecimento ou imaginação, as portas foram abertas? Os softwares para o gerenciamento das imagens e obtenção de dados já estão desenvolvidos em nível que permite a manipulação das imagens após sua tomada. Softwares tradicionais de análise cefalométrica, tal como o Dolfin, já estão adaptados à utilização dos dados tridimensionais gerados pela tomografia Cone Bean, de forma a permitir medições tridimensionais em qualquer perspectiva. Como bem definiu um aluno meu, a cabeça pode 
ser inspecionada como se estivéssemos tirando uma carta ou um conjunto de cartas de um baralho ou mesmo vendo partes ou o baralho completo de diferentes perspectivas ou pontos de vista. É realmente incrivel!

\section{1) Com relação ao Board Brasileiro de Or- todontia, quais benefícios ele traz ao especia- lista na sua prática clínica diária? Daltro Enéas Ritter}

Considero que o benefício que o Board traz ao especialista em Ortodontia é, inicialmente, a oportunidade de realizar uma auto-avaliação dos tratamentos realizados até o momento em sua clínica. $\mathrm{Na}$ escolha dos casos que serão submetidos ao exame do Board, o profissional se depara com a realidade dos procedimentos que adotou em sua prática clínica, isto é, tanto as qualidades quanto as falhas e deficiências ficam evidentes. Esta auto-avaliação pode ser extremamente benéfica se for assimilada pelo profissional e se gerar correções de rumo ou estabelecimento de novas metas e novos critérios de tratamento. Num segundo momento, a avaliação a que submete seus casos e condutas pode trazer uma satisfação pessoal de ver referendado seu esforço e dedicação ou ainda de poder discutir alternativas, exibir seu ponto de vista e experiência, de viver um momento único. O Board traz consigo um protocolo de obtenção dos dados de diagnóstico, forma de apresentação e estabelecimento de metas a serem alcançadas ao final do tratamento ortodôntico. Este protocolo e metas elevam a obtenção dos resultados ortodônticos a patamares de excelência, com reflexo no fornecimento de um serviço clínico de qualidade e altamente benéfico ao paciente. O Board não deve ser visto como um movimento elitista ou propriedade de qualquer grupo que seja ou mesmo cerceador das atividades do clínico, mas sim como algo a almejar, um caminho, um amadurecimento pessoal. Acredito que o Board deveria encampar um programa de educação continuada para que o especialista não se acomodasse nunca. Como professor e pesquisador, tenho critérios rígidos e uma autocrítica aguçada que não me permitem sofrer esta acomodação, que me impulsionam sempre no sentido de avançar, melhorar, conhecer e evoluir e o Board é um caminho lógico a seguir neste sentido.

12) Pela sua experiência como professor, na sua opinião, qual seria o tempo ideal para duração e freqüência de um curso de especialização em Ortodontia para a formação profissional ideal? Daltro Enéas Ritter

Considero que o tempo ideal de duração de um curso de especialização deveria ser aquele necessário à exposição do aluno a todas as fases de um tratamento ortodôntico, que é de aproximadamente 30 meses. Se o pretendente a especialista não tiver nenhuma experiência ou exposição a conceitos básicos de Ortodontia, recomendaria 6 meses adicionais para sua iniciação, que totalizariam um ideal de 36 meses. Em Araraquara, na Faculdade de Odontologia da Unesp e no Gestos (Grupo de Estudos Ortodônticos), temos acumulado uma vasta e longa experiência, que permite dizer que a freqüência de 1 semana por mês é suficiente para transmitir uma boa formação. Este período é complementado por tarefas práticas, leitura de artigos direcionados e no preparo de seminários clínicos e científicos que devem ser realizados no período que o aluno está em seu local de origem, já que não exigiriam a presença física no local do curso. Ainda, neste período que o aluno não está realizando o curso, ele tem a possibilidade de se dedicar a sua clínica odontológica, mantendo o contato com outras áreas da Odontologia, experiência fundamental na gestão, organização e condução de suas atividades. As despesas de deslocamento e gastos de hospedagem e refeições neste formato de curso representam uma grande vantagem para os alunos que moram em locais distantes. $\mathrm{O}$ uso de internet $\mathrm{e}$ e-mail como forma de comunicação e como recurso auxiliar na formação dos alunos, pela disponibilização de material de referência, são outros pontos que têm contribuído de forma progressiva no rol de atividades complementares e que devem constar do programa de um curso de especialização atual. Acredito também que um corpo docente bem preparado é de fundamental importância para dar 
os suportes clínico, didático e científico necessários. Neste aspecto, o corpo docente deveria ser constituído em sua maioria por doutores (75\%) e clínicos com longo tempo de atividade (25\%).

13) Quais os recentes tópicos pesquisados nos cursos de pós-graduação da Unesp de Araraquara que mais lhe entusiasmam? Daltro Enéas Ritter

No curso de pós-graduação da Unesp de Araraquara, tenho seguido uma linha de pesquisa clínica aplicada. Desde a minha formação básica, venho me dedicando ao estudo da interferência dos problemas respiratórios no crescimento e desenvolvimento craniofacial, da interferência de problemas funcionais no desenvolvimento mandibular, especificamente da mordida cruzada posterior unilateral, e a estudos sobre a influência do tratamento ortopédico no crescimento mandibular e condilar, aos quais aplico os conceitos e resultados obtidos nos estudos sobre o crescimento natural de côndilo e da fossa articular. Para completar, tenho trabalhado com maturação óssea e desenvolvimento dos ossos da mão e punho e vértebras cervicais. Tenho participado de outros trabalhos clínicos prospectivos e auxiliado na elaboração da metodologia e análise de vários trabalhos, face à formação científica que adquiri trabalhando, principalmente, com o prof. Peter H. Bushang em meu pós-doutorado em Dallas no Texas, no período de 1996 a 1997, e no curso sobre Clinical Trials e Bioestatística que realizei em Seattle - Washington neste período.

14) Sabendo da importância da Ortopedia Funcional dos Maxilares e da Ortopedia Facial em pacientes em crescimento, o senhor acredita que a avaliação das vértebras em telerradiografias em norma lateral seja um meio fiel para avaliação da fase de desenvolvimento do paciente? Paulo Cesar Raveli Chiavini

O desenvolvimento dos ossos da mão e punho e vértebras cervicais com a finalidade de avaliação do nível de maturidade esquelética e determinação da idade óssea tem sido uma área pela qual tenho me interessado e pesquisado. Tenho efetuado me- dições objetivas da largura, altura e concavidade da cinco primeiras vértebras cervicais, numa tentativa de comprovar as observações subjetivas sobre a forma e concavidade inferior destas estruturas, conforme indicado por Lamparski e outros pesquisadores. Tenho encontrado fracas correlações nestas comparações, indicando que a forma e concavidade das vértebras são variáveis e que, portanto, quando utilizadas na determinação da maturidade esquelética do indivíduo, podem conferir um alto grau de imprecisão. Este fato já havia sido relatado pelo próprio Lamparski que, em 1972, ao procurar descrever as alterações morfológicas das vértebras no decorrer do desenvolvimento, verificou ocorrer uma superposição de características em grupos etários contíguos. O significado desta superposição pode ser exemplificado pela constatação de que um determinado indivíduo com menos maturidade e pertencente ao grupo de 12 anos apresenta o mesmo nível de maturidade que outro indivíduo, mais maduro e pertencente ao grupo de 11 anos. Se por um lado este resultado indica variabilidade, por outro lado, esta superposição auxilia na determinação de uma seqüência de maturidade do indivíduo menos maduro ao mais maduro, uma vez que cada grupo começa com características observadas no grupo prévio e termina com características do grupo subseqüente. $\mathrm{O}$ intervalo entre um estágio e outro de maturação vertebral, obtido de forma subjetiva, é muito amplo e, com esta sobreposição de limites, pode gerar erros de interpretação. A coincidência entre o pico máximo de crescimento das vértebras cervicais, mandibular, estatural e dos ossos da mão é menor que 50\%, mas aumenta para mais de $80 \%$ quando se considera um intervalo de tempo de até 1 ano antes e após o surto de crescimento pubertário. Isso nos leva a concluir que este tipo de indicador relativo de maturidade apenas indica tendências e não é preciso o suficiente para prever o crescimento mandibular e assim ser utilizado para o planejamento do tratamento ortodôntico. Apesar dos trabalhos indicarem a validade e aplicabilidade das vértebras cervicais na avaliação da maturidade esquelética do paciente devemos considerar esta variabilidade, imprecisão, alto grau de subjetividade 
implícito e a dificuldade na classificação dos eventos utilizados como base. A informação obtida na maioria das vezes não é diferente daquela que se obteria pela observação da idade cronológica. Os estágios de formação óssea da mão e punho ainda cosntituem um método que dá informações mais precisas e úteis sobre o estágio de maturidade do indivíduo e sua relação com o surto de crescimento pubertário. Assim, mais estudos são necessários sobre as vértebras cervicais até que se chegue ao nível de conhecimento que temos sobre o desenvolvimento dos ossos da mão e punho.

15) Com relação à utilização de aparelhos de avanço mandibular ou reposicionamento dentário no rebordo alveolar do paciente, como o senhor observa os resultados obtidos com o aparelho de protração mandibular (APM) proposto por Coelho? Seria indicado utilizar este tipo de aparelho para compensação da Classe II de Angle em pacientes adultos? Paulo Cesar Raveli Chiavini

Sim, o aparelho de protração mandibular (APM) constitui-se num aparelho simples, engenhoso e de baixo custo, que tem como característica uma ação recíproca maxilo-mandibular. Sua ação baseia-se na propulsão mandibular rígida, tal qual a obtida pelo aparelho de Herbst, do qual derivou. Em pacientes jovens, podemos esperar alguma resposta esquelética, resumida à restrição de crescimento anterior da maxila e de estímulo ao crescimento anterior da mandíbula, mas mesmo com sua utilização em fases ideais de crescimento (durante o surto de crescimento pubertário), prevalecem as respostas dentárias representadas pela distalização de dentes superiores e mesialização de dentes inferiores. Porém, em adultos, sua ação é preponderantemente dentoalveolar, com acentuada vestibularização dos dentes inferiores e distalização dos dentes superiores e verticalização dos dentes anteriores superiores. Assim, este aparelho deve fazer parte do arsenal do ortodontista, sendo indicado para o tratamento da Classe II dentoalveolar ou para a camuflagem de problemas esqueléticos suaves em pacientes adultos. Sua ação se assemelha à de aparelhos do tipo Jasper Jumper, Forçus, Herbst, Cantilever Bite Jumping, dentre aqueles que tenho utilizado mais freqüentemente na minha prática clínica.

16) A respeito da utilização de miniparafusos de ancoragem ortodôntica tem-se utilizado os mesmos para diversos movimentos dentários em Ortodontia, sendo que algumas empresas nacionais e internacionais vêm desenvolvendo alguns parafusos de diâmetro maior e comprimentos menores para receber maior quantidade de força. $O$ senhor acredita que estes parafusos possam ter aplicabilidade clínica efetiva quando utilizados na Ortopedia Facial e Funcional? Paulo Cesar Raveli Chiavini

Fiz algumas considerações sobre os miniimplantes ou miniparafusos na questão 8 , assim complementando, estes ainda estão sendo estudados e existe a necessidade de mais pesquisas para dimensionar seu uso e aplicação. Seu uso como ancoragem ortodôntica, retração ou protração dentária, distalização de dentes, para intrusão ou extrusão dentária, verticalização dentária, dentre outras aplicações, está embasado em fundamentos e conhecimentos básicos, que ainda necessitam ser aprofundados. Sua aplicação na Ortopedia Facial e Funcional ainda não tem base teórica ou experimental, mas pode-se conceber algumas aplicações, tais como na protração maxilar em substituição à anquilose intencional de caninos decíduos.

17) $O$ fechamento de espaços é uma rotina no consultório ortodôntico. Existem vários recursos para se realizar tal manobra, mas na maioria dos casos não se conhece o sistema de força liberado. Qual a vantagem de se usar sistemas de forças da mola $T$ segundo a filosofia de Burstone, preconizada pela FOArUnesp? Dirceu Barnabé Raveli

Caro Dirceu, nós (Luiz, Lídia, você e eu) temos cada vez mais trabalhado com a mola $\mathrm{T}$, a ponto de obtermos completa familiaridade com todos os aspectos envolvidos na sua construção, ativação e aplicação clínica. Hoje, estamos num estágio de 
entendimento sobre a mola $\mathrm{T}$ que nos permite dizer que sua grande vantagem é a possibilidade de determinação do sistema de forças gerado nos segmentos anterior e posterior (força horizontal e momentos gerados nos segmentos alfa e beta) e do conhecimento prévio da proporção momento/força e carga/deflexão gerada pela mola (baseado nos estudos realizados em Araraquara), que nos orientam com relação ao tipo de movimento que ocorrerá conforme a mola vai desativando (inclinação controlada, translação e correção radicular). Os trabalhos do Roberto Shimizu e Ricardo Sampaio, dentre outros, sobre a quantidade de ativação, as pré-ativações, tipos e espessuras de fios utilizados na confecção da mola $\mathrm{T}$, fornecem estes elementos referenciais para sua utilização. As alças T atuam por um longo período de tempo e produzem uma grande amplitude de movimento dentário de um dente único (tal como retração de caninos) ou de grupos de dentes (tal como segmento anterior ou posterior), com controle de ancoragem máximo, médio ou mínimo. Esta mola libera forças leves e contínuas, produzindo movimentos dentário com mínimo dano biológico, representado pelas reabsorções radiculares ou ósseas. Talvez a única desvantagem que poderia relacionar é que esta alça é volumosa e pode provocar injúrias aos tecidos moles, que podem ser perfeitamente prevenidas se construída de forma adequada ou com pequenos ajustes periódicos. A sua aplicação de forma rotineira, nos cursos de especialização e pós-graduação que nosso grupo tem coordenado em Araraquara e Sertãozinho, nos permite concluir que esta mola é um recurso valioso no fechamento de espaços e que pode ser assimilada de forma efetiva em pouco tempo, após a introdução nos conceitos de biomecânica da técnica do arco segmentado de Burstone. Com relação à sua aplicação na prática clínica, posso dizer, tal como o prof. Marcotte diz, que está presente em $25 \%$ dos meus casos tratados, principalmente em pacientes adultos e casos complexos, nos quais a mecânica convencional de arco contínuo e de deslizamento trariam resultados desastrosos e movimentos dentários indesejáveis e incontroláveis.
18) Prof. Ary, sei do seu envolvimento com pesquisas utilizando diferentes aparelhos ortopédicos funcionais, então, para você qual seria a importância dos surtos de crescimento pubescente individuais para $o$ tratamento ortopédico? Dirceu Barnabé Raveli

Os aparelhos ortopédicos funcionais têm sido utilizados com a finalidade de interferir nos processos de crescimento e desenvolvimento dentoalveolar e esquelético naturais. $\mathrm{Na}$ maioria das vezes, uma maior ação esquelética é desejada e no período do surto de crescimento pubescente este efeito pode ser otimizado. $\mathrm{O}$ crescimento sutural maxilar e o crescimento condilar da mandíbula têm seu ritmo de crescimento associado ao crescimento geral ou estatural, que na puberdade sofre uma aceleração. Quando medimos a altura e o ritmo de crescimento estatural de uma criança, estamos medindo basicamente o crescimento que ocorre no tecido cartilaginoso das extremidades ósseas, que é um evento seqüencial que finalizará quando ocorrer a completa ossificação destas extremidades ósseas, culminando com o final do crescimento. Estimativas da maturação esquelética têm, portanto, o objetivo de estimar o grau de progressão deste processo. No surto de crescimento pubescente, como sabemos, existe a aceleração da velocidade de crescimento, catalizado pela liberação dos hormônios sexuais, assim, é importante que se determine com precisão o quanto estamos próximos, dentro ou distantes deste surto. A forma clássica de determinação da fase em que o paciente se encontra é pela avaliação da maturidade esquelética, obtida pela observação dos estágios de formação dos ossos da mão e punho. As idades cronológicas, dentárias e vertebrais podem ser utilizadas, mas são variáveis e apresentam menores correlações com a idade óssea craniofacial. Você tem contribuído muito para o conhecimento nesta área, com trabalhos a respeito de avaliação da idade dentária e vertebral. De forma geral, dentre as três dimensões que podemos atuar com os aparelhos ortopédicos funcionais, a transversal é a que se define mais precocemente, já na infância, requerendo uma intervenção mais precoce em 
termos de maturidade. A dimensão sagital terá seu potencial esgotado somente após a puberdade, na fase adulta jovem, assim o conhecimento da época do surto de crescimento individual do paciente é importante para que possamos atuar de forma efetiva nesta dimensão. Por fim, a dimensão vertical tem potencial se estendendo por um longo período na fase adulta, bem além do surto do crescimento pubescente e é a dimensão na qual temos um tempo mais longo para atuar, mas também é afetada de forma significativa pelo surto de crescimento pubescente.

19) Com o atual avanço tecnológico e a velocidade com que ocorrem mudanças, qual seria para você 0 paradigma de sucesso na Ortodontia atual e qual o caminho para a excelência? Dirceu Barnabé Raveli

O maior paradigma da Ortodontia é a resolução de problemas esqueléticos, visto que somos limitados na tentativa de modificação do padrão esquelético inerente do nosso paciente. Pacientes dolicofaciais, braquifaciais, retrognatas ou prognatas são desafiadores e na maioria das vezes conseguimos, com nossa terapia ortodôntica ou ortopédica, mascarar ou camuflar o padrão do paciente. Em Ortodontia faltam protocolos de tratamento definidos para as más oclusões, o que em parte resulta da falta de um conhecimento mais profundo dos aspectos envolvidos na natureza, desenvolvimento, conseqüências e formas de tratamento das más oclusões. O sucesso em Ortodontia pode ser medido no grau de satisfação dos pacientes com relação aos resultados alcançados e na resolução das más oclusões de forma sistemática e efetiva. O caminho para a excelência é o conhecimento acumulado ao longo do tempo aplicado na sua totalidade, com disposição e afinco.

20) Quando fazemos uso de aparelhos ortopédicos para correção da Classe II, quais seriam as alterações que ocorreriam no côndilo e fossa glenóide? Dirceu Barnabé Raveli

Na correção da Classe II com aparelhos ortopédicos, o mecanismo de interferência no cresci- mento condilar é derivado da propulsão mandibular. Conforme expliquei anteriormente, existe alteração na direção do crescimento do côndilo para posterior, resultado do estiramento de tecidos moles (cápsula e ligamentos articulares) que se inserem na cabeça da mandíbula. Este estiramento modifica o padrão de remodelação da cabeça da mandíbula e promove um aumento da atividade celular (mitoses de condroblastos) em sua região póstero-superior, que direciona o crescimento condilar mais para posterior e superior, semelhante ao crescimento condilar que ocorre em paciente dolicofaciais. Assim, a propulsão mandibular tende a alterar a morfologia mandibular para um padrão mais vertical, que é desejado em pacientes braquifaciais e indesejado em dolicofaciais. A fossa articular, por sua vez, apresenta um padrão de remodelação com aposição óssea em toda superfície articular, com diminuição de sua profundidade, influenciada pelo mesmo mecanismo de modificação condilar (estiramento da cápsula e ligamentos articulares), contribuindo para o desenvolvimento vertical da região posterior. A eminência articular tende a ter sua inclinação suavizada. Estuda-se ainda a possibilidade dos aparelhos ortopédicos influírem no deslocamento da fossa articular para baixo e para trás, que é resultado do crescimento que ocorre na sincondrose esfenoccipital, que desloca o osso occipital e indiretamente o osso temporal, onde a fossa se localiza, na mesma direção.

21) Os pacientes com problema vertical continuam sendo um desafio para os clínicos. Qual seria o enfoque mais atual para a resolução desse problema em indivíduos com e sem crescimento? Dirceu Barnabé Raveli

O conhecimento que você adquiriu nos seus dois anos de pós-doutorado, em Toronto no Canadá, e compartilhou conosco, a respeito do tratamento de problemas verticais, tem causado um grande impacto no meu entendimento e conhecimento a respeito da atuação do apoio de acrílico interposto entre os dentes posteriores sobre o padrão de erupção dentária e de crescimento maxilomandibular. Quando este apoio de acrílico é construído 
com altura maior que $3 \mathrm{~mm}$, sua ação passa a ser de protrusão dos arcos dentários e maxilomandibular, devido à incidência das forças mastigatórias ser mais oblíqua em relação ao longo eixo dentário. Quando construído com altura igual ou menor que $3 \mathrm{~mm}$, sua ação passa a ser de restrição da erupção dentária, pela incidência destas forças ser ao longo do eixo dentário, afetando o crescimento vertical dentoalveolar com rotação mandibular anti-horária, diminuição da convexidade facial e fechamento da mordida aberta. Esta abordagem pode ser aplicada a pacientes com problemas verticais com potencial de crescimento, com a utilização do Bite block ou aparelhos ortopédicos com cobertura oclusal posterior. Em pacientes adultos sem crescimento, com problema vertical suave, esta abordagem aplicada na forma do Bite block ou associada à força extrabucal vertical (Thurow modificado), conforme mencionei anteriormente, pode ser decisiva na resolução do problema. Em pacientes adultos com mordida aberta esquelética, dolicofaciais, temos aplicado com sucesso o Sistema de Ancoragem Esquelética (SAS), que consiste em placa de titânio fixada ao pilar zigomático. Os dados do trabalho de tese realizado em nosso curso de pós-graduação e resultados de casos tratados permitem dizer que o SAS é a melhor opção para intrusão do segmento posterior, mesmo considerando a possibilidade de utilização dos miniparafusos, que indicaria para intrusão de dentes isolados. A solução definitiva para pacientes verticais com excesso maxilar vertical é a cirurgia ortognática, sem sombra de dúvida.

22) Considerado um dos expoentes da pesquisa científica no Brasil, como o senhor analisa a influência do crescimento vertical da face no desenvolvimento da má oclusão? Roberto Hideo Shimizu

No padrão de crescimento dolicofacial ou vertical, existe uma tendência à redução no perímetro do arco pelo padrão de erupção dos dentes anteriores mais para posterior, o que traz como conseqüência a falta de espaço ou apinhamentos dentários. Os arcos dentários apresentam largura diminuída, agravando a falta de espaço e dificul- tando o correto alinhamento dos dentes. A largura facial diminuída, característica do indivíduo com padrão vertical, é acompanhada por uma largura diminuída da cavidade nasal, que aumenta a resistência à passagem de ar, dificultando a respiração nasal. Pequenos aumentos teciduais da amígdala faringeana (adenóide), tubária, palatina (amígdala) e lingual, edemas da mucosa nasal, como nos casos de rinite alérgica, desvios de septo e obstruções teciduais ou anatômicas outras, causam uma respiração bucal, que por sua vez agrava o padrão vertical de crescimento. $\mathrm{O}$ aumento da altura facial anterior muitas vezes não é acompanhado por um aumento proporcional no comprimento dos lábios superior e inferior, que dificulta o selamento labial e favorece a respiração bucal. Na respiração bucal, alterações posturais de lábios, língua e mandíbula promovem alterações dentoalveolares (excesso de erupção de dentes posteriores e anteriores, atresia maxilar, mordidas cruzadas posteriores e abertas anteriores) e esqueléticas (agravamento do padrão vertical de crescimento, aumento da convexidade facial, rotação mandibular para baixo e para trás).

23) Respaldado no seu elevado nível científico, adquirido na pós-graduação de Araraquara e no convívio com o professor Peter $\mathrm{H}$. Bushang (Baylor College of Dentistry, Dallas - Texas) durante o seu pós-doutorado, como - professor avalia a tendência da pesquisa científica no Brasil? Roberto Hideo Shimizu

Complementando o que já respondi no questionamento 4, considero que na área da Ortodontia, estamos entrando numa fase de maturidade científica e de grande desafio. A pesquisa hoje no Brasil atinge níveis e padrões muito elevados, que requerem dos que se dedicam a ela muita perseverança, conhecimento e dedicação. Hoje grupos de pesquisa com linhas e objetivos muito bem delimitados são essenciais na manutenção deste padrão alcançado.

24) Sendo a respiração bucal uma das linhas de pesquisa de sua escola. Qual o protocolo que o senhor sugere para estes pacientes na 
anamnese, no tratamento e na proservação? Roberto Hideo Shimizu

$\mathrm{Na}$ respiração bucal, é importante que se faça um bom exame clínico, anamnese e exame radiográfico, para se determinar o fator etiológico desta alteração funcional. No exame clínico e anamnese, podemos verificar a presença de obstruções teciduais e anatômicas, tais como amígdalas hipertróficas, desvios de septo e rinites alérgicas. $\mathrm{O}$ exame da telerradiografia lateral pode evidenciar hipertrofias de adenóide e amígdalas lingual e palatinas, hipertrofia de cornetos nasais ou da cauda do corneto inferior. $\mathrm{Na}$ telerradiografia frontal ou panorâmica podemos verificar se os cornetos nasais médio e inferior estão normais ou hipertrofiados, obstruindo a cavidade nasal, se existe desvio de septo nasal, se os seios maxilares estão normais ou velados (sinusites), se existem patologias ou outros achados. A remoção do fator etiológico da respiração bucal e normalização da respiração para um padrão nasal são importantes na estabilidade do tratamento ortodôntico. O auxílio do médico otorrinolaringologista, da fonoaudióloga e do fisioterapeuta é importante no diagnóstico e tratamento do paciente respirador bucal. Em pacientes com atresia maxilar e mordida cruzada posterior, a disjunção palatina tem produzido diminuição da resistência nasal e melhora no padrão respiratório, desde que a causa da respiração bucal não seja obstrução naso ou buco-faringeana.

25) Professor Ary, o senhor considera importante o pós-graduando em Ortodontia ter o conhecimento e a prática de Edgewise em sua formação? Roberto Hideo Shimizu

O ortodontista deve ter conhecimento profundo dos aspectos biológicos e mecânicos envolvidos na utilização dos diversos tipos de aparelhos, destreza manual, sensibilidade para detectar os desvios da normalidade e habilidade para traçar metas e definir formas de atuação. Deve ter ainda flexibilidade na forma de atuação, isto é, deve ser capaz de encontrar alternativas e soluções similares na condução do tratamento da má oclusão, aliando perseverança e grande poder de persuasão para que suas instruções sejam seguidas pelo paciente.
Assim, como forma de adestramento, a técnica Edgewise convencional torna-se um recurso importante, diria até essencial. Charles H. Tweed, pessoa de mente brilhante e talentosa, aluno do prodigioso Edward $\mathrm{H}$. Angle, abraçou a idéia do desenvolvimento do aparelho Edgewise e revolucionou o conhecimento e prática da Ortodontia. Sua lição foi aprendida, constituindo-se nos alicerces da Ortodontia corretiva, que continuam sendo aperfeiçoados até os dias de hoje. Bandas pré-fabricadas, colagem direta dos braquetes, incorporação de compensações nos braquetes para as diferenças vestíbulo-linguais, inclinações e angulações das coroas dentárias podem ser citados. $\mathrm{Na}$ atualidade, novos conceitos biomecânicos e procedimentos foram agregados à mecânica desenvolvida por Tweed. A evolução dos materiais odontológicos, em especial dos fios de ligas alternativas ao aço inoxidável (cromo-níquel), como cobre, titânio, molibdênio e fios térmicos com mudança de fase austenítica e martensítica com a variação da temperatura bucal, tornaram imprescindivel a utilização de braquetes pré-angulados e pré-torqueados na clínica diária. Assim, a técnica Edgewise, como foi concebida inicialmente por Tweed, deve fazer parte integrante da formação técnica de base do ortodontista, mas, assim como o aluno sobrepujou o mestre mostrando evidências claras e inegáveis de seus conceitos e métodos, evoluindo a passos largos, nós temos a obrigação de ir adiante e também evoluir. Esta é a linha mestre da Ortodontia de Araraquara, da qual você teve oportunidade de participar e desfrutar.

\section{6) O senhor é um dos professores que preconiza a técnica do arco segmentado de Burstone. Qual o diferencial que esta filosofia apresenta em relação às demais? Roberto $\mathrm{Hi}$ -} deo Shimizu

A técnica de arco segmentado (TAS) tem como característica ser uma filosofia contemporânea, originada de conceitos biomecânicos, que se aplica a qualquer sistema de braquetes existente no mercado. Nesta técnica aplica-se o conceito de dois dentes, onde é possível se estabelecer quais serão os elementos ativos (que serão movimentados) e reativos 
(que servirão de ancoragem) facilitando o entendimento e controle do sistema de forças a ser aplicado. A segmentação aumenta a distância entre os pontos de aplicação de forças, criando espaço para amplas ativações dos dispositivos construídos com fios de alto coeficiente de elasticidade, que geram baixa proporção carga/deflexão. Esta baixa proporção carga/deflexão tem a vantagem de resultar na liberação de forças leves e constantes, que minimizam as alterações direcionais no movimento dentário, evitam danos biológicos e aceleram a movimentação dentária. A TAS ainda permite a utilização de dispositivos pré-fabricados e pré-calibrados, o que aumenta a eficiência clínica e também dá maior precisão para o ortodontista no controle das forças aplicadas. Alguns exemplos são as alça em T, arcos de intrusão, braços de alavanca (cantilever), alças retangulares, barra palatina e arco lingual, dentre outros. Estes recursos são utilizados hoje de forma rotineira e na maioria dos tratamentos, principalmente naqueles de alta complexidade, que requeiram amplas movimentações, ou onde as estruturas de suporte estejam comprometidas e em pacientes adultos, constituindo o alicerce da mecânica ortodôntica.

27) Como o senhor avalia o ensino da Ortodontia na graduação e na pós-graduação stricto-sensu das universidades brasileiras. Da mesma forma, e o ensino de Ortodontia nas especializações ministradas nos institutos de ensino superior? Roberto Hideo Shimizu

Existe uma diferença fundamental nos objetivos, carga horária e periodicidade do curso de especialização para o de mestrado. No curso de mestrado, a presença em tempo integral é requerida, de forma a favorecer a incorporação de conceitos básicos, noções fundamentais e específicas, preparo filosófico, didático e científico. A produção tecnológica e científica ocupa grande parte do tempo dos mestrandos. No curso de especialização, o objetivo é a formação e adestramento técnico para o exercício da profissão, que exige menor tempo e esforço. As universidades brasileiras têm um compromisso inerente com o desenvolvimento científico da profissão, havendo um estímulo e até cobrança neste sentido, que as diferencia de institutos de ensino superior, que na maioria das vezes são de iniciativa privada e regulados pelas leis de mercado, com mínima vocação científica, que gera altos custos, investimento em infra-estrutura, suporte material e pessoal e demanda de profissionais altamente qualificados.

\footnotetext{
Adriano Marotta Araujo

- Doutor em Ortodontia - UNESP / Araraquara.

- Pós-graduado na Baylor College of Dentistry - Dallas, TX.

- Professor na Disciplina de Ortodontia - UNESP / São José dos Campos.
}

Ricardo Sampaio de Souza

- Mestre e Doutor em Ortodontia e Ortopedia Facial - UNESP / Araraquara.

- Professor Titular da Disciplina de Ortodontia Preventiva e Interceptadora - UNIPAR / Cascavel.

- Coordenador do Curso de Especialização em Ortodontia da UNIPAR / Cascavel.

Daltro Enéas Ritter

- Especialização e Mestrado em Ortodontia - UERJ / Rio de Janeiro.

- Doutorado em Ortodontia - UNESP / Araraquara.

- Professor do Curso de Especialização em Ortodontia da UFSC / Florianópolis.

Paulo Cesar Raveli Chiavini

- Professor pós-graduação e mestrado em Ortodontia do Centro Universitário Hermínio Ometto - Araras/SP.

- Professor Titular dos cursos de especialização em Ortodontia da Universidade de Santo Amaro - São Paulo; Universidade Regional de Blumenau - SC e CESTEP/Unievangélica - Tocantins.

- Mestre e Doutor em Ortodontia pela UNESP / Araraquara.

- Especialista em Radiologia pela USP- FUNBEO / Bauru.

Dirceu Barnabé Raveli

- Professor Adjunto na Disciplina de Ortodontia, - UNESP / Araraquara.

- Vice-coordenador do Programa de pós-graduação em Ciências Odontológicas e responsável pela área de Ortodontia.

- Pós-Graduação em Ortodontia na Faculdade de Odontologia da Universidade de Toronto-Canadá.

\section{Roberto Hideo Shimizu}

- Mestre e Doutor em Ortodontia e Ortopedia Facial pela Faculdade de Odontologia de Araraquara - UNESP.

- Professor Adjunto Doutor da Disciplina de Ortodontia da Universidade Tuiuti do Paraná (UTP-PR).

- Coordenador do Curso de Especialização em Ortodontia da UTP-PR.

- Professor da Pós-graduação em Ortodontia da ABO-Cascavel e ABO-São José dos Pinhais. 